particularly, just a dozen printed on Danish soil are enumerated in the list. Three of them have disappeared completely, and the remaining nine muster between them sixteen copies, besides a few fragments. The British Museum possesses none of them, nor apparently does any other library in the Kingdom.

Victor Scholderer.

\title{
THE N-TOWN PLAYS 1
}

Miss Swenson's study of this curious cycle is the fullest that has yet appeared. It seems to have been written in the autumn of 1913 and was printed in October 1914; my own Sandars lecture on the subject was delivered in November 1913 and printed a year later: our investigations were therefore quite independent. That we arrived at generally similar conclusions is largely due to our having both attacked the problem through a comparison of the prologue with the actual text. By this and other subsidiary means Miss Swenson has discovered much concerning the history of the plays, though there remains perhaps even more that patient research may be expected to reveal. For one thing she has by no means exhausted the information that can be extracted from the material make-up of the volume. Thus she has observed the successive catchwords on fol. 148b, but she has failed to notice that they correspond to the successive insertion of leaves after that indicated. The manuscript simply

1 An Inquiry into the Composition and Structure of Ludus Coventriac, by Esther L. Swenson, with a Note on the Home of Ludus Coventriae by Hardin Craig. (University of Minnesota. Studies in Language and Literature. Number 1.) Minneapolis, Bulletin of the University of Minnesota, October 1914. (Large 8vo, 83 pages.) 
bristles with clues, and when these have all been properly followed up we shall know a great deal more than we do now about the anatomy of the cycle, and when its component parts as thus revealed have been subjected to further linguistic, metrical, and structural analysis we may know something of their origin. Such an investigation will necessarily be far more detailed, and I fear much longer, than Miss Swenson's, which is however, meanwhile, most welcome as a helpful contribution to the subject.

If I have any criticism to make of Miss Swenson's method it is that she is somewhat too fond of a priori assertions as to what the nature of a particular play should be. That the Veronica story 'comes from a legendary source, such as would probably not have been used in this cycle at the time of the writing of the Prologue', is rather too dogmatic a statement for a really critical study. As regards details, I am inclined to doubt whether Miss Swenson has sufficiently analysed the Prologue itself. That it belongs to a quite early stage in the development of the cycle, if not to the very nucleus, there is no manner of doubt. On the other hand it has not come down to us in quite its original form. Miss Swenson suspects two plain quatrains (the manuscript leaves blanks for the completion of the stanzas) of being interpolations. They no doubt are ; but it is also more than probable that certain stanzas in the Passion section have been re-written to suit the altered text at a quite late, though perhaps not the latest, point in its career.

The final paragraphs of the study are devoted to attempting an answer to the question: How was the cycle performed ? In my view this is an illegitimate question admitting of no reply, because the cycle as we have it was never meant for performance. It is easy to show that the cycle first took its present shape in the extant manuscript, and the marginal notes and genealogies clearly prove this to have been pre- 
pared for literary and not for theatrical use. The numerals by which the cycle is throughout divided into separate plays are no evidence of representation, but are inserted merely to introduce some sort of correspondence with the Prologue. On the other hand it is exceedingly difficult to determine how far the amalgamation of heterogeneous material was first effected in the existing manuscript. But in any case it is only to the constituent portions of the cycle, whether united in 1468 or at an earlier period, that the question of representation can be properly taken to apply. Some of these, the Childhood of Mary and the Passion, are in the main intended for representation on a great stationary and multiple stage, with a number of domi or 'schaffaldys'. Other portions, the Old Testament and liturgical Resurrection plays, have every appearance of being in origin processional, though the former group at least has been contaminated from a stationary source. The Assumption, if intended for representation at all, was most likely performed, as Miss Swenson suggests, in the nave of some great church. That no attempt has been made to harmonize these various modes of representation is perhaps the strongest of all arguments for supposing that performance of the whole cycle was never contemplated: the Prologue and the various and contradictory allusions to actual representation in the text itself all belong to contributary sources.

Professor Hardin Craig's note collects the evidence in favour of. Lincoln as the home of the cycle. But he needs first to show that this phrase has any meaning.

W. W. Greg. 